\title{
Attenuation by incretins of thyroid hormone-stimulated osteocalcin synthesis in osteoblasts
}

\author{
SHINGO KAINUMA ${ }^{1,2}$, HARUHIKO TOKUDA ${ }^{2,3}$, KAZUHIKO FUJTA $^{1,2}$, TETSU KAWABATA $^{1,2}$, GO SAKAI $^{1,2}$, \\ RIE MATSUSHIMA-NISHIWAKI ${ }^{2}$, ATSUSHI HARADA ${ }^{4}$, OSAMU KOZAWA ${ }^{2}$ and TAKANOBU OTSUKA ${ }^{1}$ \\ ${ }^{1}$ Department of Orthopedic Surgery, Nagoya City University Graduate School of Medical Sciences, Nagoya, Aichi 467-8601; \\ ${ }^{2}$ Department of Pharmacology, Gifu University Graduate School of Medicine, Gifu 501-1194; Departments of ${ }^{3}$ Clinical \\ Laboratory and ${ }^{4}$ Orthopedic Surgery, National Center for Geriatrics and Gerontology, Obu, Aichi 474-8511, Japan
}

Received September 12, 2016; Accepted October 26, 2016

DOI: $10.3892 /$ br.2016.798

\begin{abstract}
Incretins, the polypeptide hormone glucosedependent insulinotropic polypeptide (GIP) and glucagon-like peptide-1 (GLP-1) secreted from the small intestine after nutrient ingestion, are generally known to stimulate insulin secretion from pancreatic $\beta$-cells. We previously demonstrated that triiodothyronine $\left(\mathrm{T}_{3}\right)$ stimulates osteocalcin synthesis at least in part through p38 mitogen-activated protein kinase in osteoblast-like MC3T3-E1 cells. In the present study, we investigated the effects of GIP and GLP-1 on $\mathrm{T}_{3}$-stimulated osteocalcin synthesis and the mechanism of action involved in MC3T3-E1 cells. GIP and GLP-1 markedly suppressed the $\mathrm{T}_{3}$-stimulated osteocalcin release. GIP and GLP-1 significantly attenuated the expression levels of osteocalcin mRNA induced by $\mathrm{T}_{3}$. The $\mathrm{T}_{3}$-stimulated transactivation activity of the thyroid hormone-responsive element was reduced by GIP and GLP-1. These results suggest that incretins repressed the $\mathrm{T}_{3}$-stimulated osteocalcin synthesis in osteoblast-like MC3T3-E1 cells, and the suppressive effect of incretins was mediated through transcriptional levels.
\end{abstract}

\section{Introduction}

Bone metabolism is strictly regulated by osteoblastic bone formation and osteoclastic bone resorption (1). Bone tissue is continuously regenerated through a process known as bone remodeling. This bone remodeling process begins with osteoclastic bone resorption, followed by osteoblastic bone formation (1). It is generally established that osteoblasts play a crucial role in the regulation of bone resorption through the expression of the receptor activator of nuclear factor $\kappa \mathrm{B}$

Correspondence to: Dr Haruhiko Tokuda, Department of Clinical Laboratory, National Center for Geriatrics and Gerontology, 7-430 Morioka, Obu, Aichi 474-8511, Japan

E-mail: tokuda@ncgg.go.jp

Key words: incretin, glucose-dependent insulinotropic peptide, glucagon-like peptide-1, triiodothyronine, osteocalcin, osteoblast ligand (RANKL) in response to a variety of bone resorptive stimuli (2). Osteoblasts express various cell type-specific markers during their differentiation process. Osteocalcin, which is synthesized by osteoblasts and recognized as a marker of mature osteoblast phenotype, is the most abundant non-collagenous protein (3). It is generally known that osteocalcin is post-translationally modified by vitamin K-dependent $\gamma$-carboxylation as bone Gla-protein (3). It has been reported that osteocalcin-deficient mice develop an increase of bone formation without impairing bone resorption, suggesting that osteocalcin is a determinant of bone formation (4). In addition, uncarboxylated osteocalcin functions as a potent hormone, which regulates energy metabolism by stimulating the insulin secretion from $\beta$-cells of pancreatic islets and upregulating the insulin sensitivity of peripheral organs such as muscle and adipose (5). Thus, bone is currently recognized to act as an endocrine organ through the release of osteocalcin.

The thyroid hormone acts as an important regulator in the skeletal function as well as whole-body metabolism. An excess of thyroid hormone, known as hyperthyroidism, upregulates the bone metabolic turnover and increases the ratio of bone resorption to bone formation, resulting in osteoporosis associated with an increased risk of bone fracture (6). It has been reported that bone mineral density is markedly decreased in untreated patients of hyperthyroidism (7). The receptor of thyroid hormone belongs to the nuclear receptor superfamily (8). The biological functions of the thyroid hormone are mainly mediated by binding to specific receptors in the nucleus, and that the receptor-hormone complex activates the transcription of related genes (9). In osteoblasts, the thyroid hormone stimulates alkaline phosphatase activity and modulates the proliferation of osteoblasts (10). Previously, we showed that triiodothyronine $\left(\mathrm{T}_{3}\right)$ stimulates osteocalcin synthesis at least in part via p38 mitogen-activated protein (MAP) kinase in osteoblast-like MC3T3-E1 cells and that the adenylyl cyclase-cAMP system regulates the osteocalcin synthesis via the suppression of p38 MAP kinase activation $(11,12)$. However, the exact mechanism underlying the thyroid hormone-induced synthesis of osteocalcin remains to be elucidated.

Incretins, endogenous polypeptide hormones released from the small intestine in response to oral food intake, 
stimulate insulin secretion from pancreatic $\beta$-cells (13). Glucose-dependent insulinotropic polypeptide (GIP) and glucagon-like peptide-1 (GLP-1), which exert their effects by the specific guanine nucleotide-binding protein (G-protein)-coupled receptors highly expressed on pancreatic islet $\beta$-cells, are currently recognized as incretins (14). Regarding the effects of incretins in bone, it has been shown that GIP stimulates the expression of collagen type I mRNA and alkaline phosphatase activity in osteoblasts (15), and ameliorates the bone mineral density in ovariectomized rat established as a model of postmenopausal osteoporosis (16). In addition, GLP-1 reportedly induces osteoblast differentiation (17). However, the roles of incretins in bone metabolism have not yet been fully clarified.

In the present study, we investigated the effects of incretins, GIP and GLP-1, on $\mathrm{T}_{3}$-stimulated osteocalcin synthesis in osteoblast-like MC3T3-E1 cells. The results demonstrated that incretins suppressed the $\mathrm{T}_{3}$-stimulated osteocalcin synthesis in MC3T3-E1 cells, and the suppressive effect of incretins was mediated through transcriptional levels.

\section{Materials and methods}

Materials. $\mathrm{T}_{3}$ was obtained from Sigma-Aldrich (cat. no. T2752; St. Louis, MO, USA). GIP (cat. no. 4178-v) and GLP-1 (cat. no. 4344-v) were purchased from Peptide Institute, Inc. (Osaka, Japan). The mouse osteocalcin enzyme-linked immunosorbent assay (ELISA) kit (cat. no. J64239) was obtained from Alfa Aesar; Thermo Fisher Scientific (Lancashire, UK). Other materials and chemicals were obtained from commercial sources. $\mathrm{T}_{3}$ was dissolved in $0.1 \mathrm{M} \mathrm{NaOH}$. The concentration of $\mathrm{NaOH}$ was $10 \mu \mathrm{M}$, which did not affect the assay for osteocalcin.

Cell culture. Cloned osteoblast-like MC3T3-E1 cells derived from newborn mouse calvaria were maintained as previously described $(18,19)$. Briefly, the cells were cultured in $\alpha$-minimum essential medium ( $\alpha$-MEM) containing $10 \%$ fetal bovine serum (FBS) at $37^{\circ} \mathrm{C}$ in a humidified atmosphere of $5 \%$ $\mathrm{CO}_{2} / 95 \%$ air. The cells were seeded in 35-mm diameter dishes $\left(5 \times 10^{4}\right.$ cells/dish) or $90-\mathrm{mm}$ diameter dishes $\left(2 \times 10^{5}\right.$ cells/dish $)$ in $\alpha$-MEM containing $10 \%$ FBS. After 5 days, the medium was exchanged for $\alpha$-MEM containing $0.3 \%$ FBS. The cells were used for experiments following a 48-h incubation period at $37^{\circ} \mathrm{C}$.

Assay for osteocalcin. The cultured cells were stimulated by $10 \mathrm{nM}$ of $\mathrm{T}_{3}$ or vehicle in $1 \mathrm{ml}$ of $\alpha$-MEM containing $0.3 \%$ FBS for the indicated periods. When indicated, the cells were pretreated with various doses of GIP or GLP-1 for $60 \mathrm{~min}$. The conditioned medium was collected at the end of incubation, and the osteocalcin concentration in the medium was then measured using the mouse osteocalcin ELISA kit according to the manufacturer's protocol.

Reverse transcription-quantitative polymerase chain reaction $(R T-q P C R)$. The cultured cells were pretreated with $100 \mathrm{nM}$ of GIP, $100 \mathrm{nM}$ of GLP-1 or vehicle for $60 \mathrm{~min}$, and then stimulated with $10 \mathrm{nM}$ of $\mathrm{T}_{3}$ or vehicle in $\alpha$-MEM containing $0.3 \%$ FBS for $48 \mathrm{~h}$. Total RNA was isolated and reverse transcribed into complementary DNA using TRIzol reagent (Invitrogen; Thermo Fisher Scientific, Inc., Beijing, China) and Omniscript Reverse Transcriptase kit (Qiagen Inc., Valencia, CA, USA), respectively. RT-qPCR was performed in capillaries using a LightCycler system with the LightCycler FastStart DNA Master SYBR-Green I (Roche Diagnostics, Basel, Switzerland). Sense and antisense primers were synthesized based on the reports of Zhang et al for mouse osteocalcin and Simpson et al for mouse GAPDH $(20,21)$. The amplified products were determined using a melting curve analysis according to the system protocol. The osteocalcin mRNA levels were normalized to those of GAPDH mRNA.

Luciferase reporter assay. A reporter plasmid, pDR4 (thyroid hormone response element)-Luc was purchased from Stratagene (Santa Clara, CA, USA). The cultured cells were pretreated with $100 \mathrm{nM}$ of GIP, $100 \mathrm{nM}$ of GLP-1 or vehicle at $6 \mathrm{~h}$ after transfection with the pDR4-Luc reporter plasmid $(1 \mu \mathrm{g} / \mathrm{dish})$ using UniFector transfection reagent (B-Bridge International, Inc., Santa Clara, CA, USA). After the pretreatment (60 min) with GIP or GLP-1, the cells were stimulated by $10 \mathrm{nM}$ of $\mathrm{T}_{3}$ or vehicle for $48 \mathrm{~h}$. The samples were lysed by passive lysis buffer (Promega Corp., Madison, WI, USA), and obtained using a cell scraper. The measurement of the luciferase activity of the cell lysates were performed using a dual luciferase reporter assay system (Promega Corp.) according to the manufacture's protocol. The cells were cotransfected with pRL-CMV (Renilla luciferase; $0.1 \mu \mathrm{g} / \mathrm{dish}$ ) as an internal standard to normalize transfection efficiency.

Statistical analysis. The data were analyzed by analysis of variance followed by Bonferroni method for multiple comparisons between pairs. $\mathrm{P}<0.05$ was considered to indicate a statistically significant difference. The data are presented as the mean \pm SEM of triplicate determinations from three independent cell preparations.

\section{Results}

Effect of GIP on the $T_{3}$-stimulated osteocalcin release in MC3T3-E1 cells. We previously reported that $\mathrm{T}_{3}$ stimulates the synthesis of osteocalcin from 48 to $96 \mathrm{~h}$ after stimulation in osteoblast-like MC3T3-E1 cells (11). In the present study, we first examined the effect of GIP, one of the incretins, on the $\mathrm{T}_{3}$-stimulated osteocalcin release in MC3T3-E1 cells. GIP, which alone did not affect the basal levels of osteocalcin, significantly reduced the $\mathrm{T}_{3}$-stimulated osteocalcin release (Fig. 1A). The suppressive effect of GIP on the $\mathrm{T}_{3}$-stimulated osteocalcin release was observed in the range between 0.03 and $100 \mathrm{nM}$ (Fig. 1B). GIP at $0.03 \mathrm{nM}$ caused an $\sim 50 \%$ decrease in the $\mathrm{T}_{3}$-effect.

Effect of GLP-1 on the $T_{3}$-stimulated osteocalcin release in MC3T3-E1 cells. The effect of GLP-1, another incretin, was examined on the $\mathrm{T}_{3}$-stimulated osteocalcin release in MC3T3-E1 cells. GLP-1, which by itself did not affect the osteocalcin release, time-dependently reduced the release of osteocalcin from $48 \mathrm{~h}$ after the $\mathrm{T}_{3}$ stimulation $\leq 96 \mathrm{~h}$ (Fig. 2A). The inhibitory effect of GLP-1 on the $\mathrm{T}_{3}$-induced 

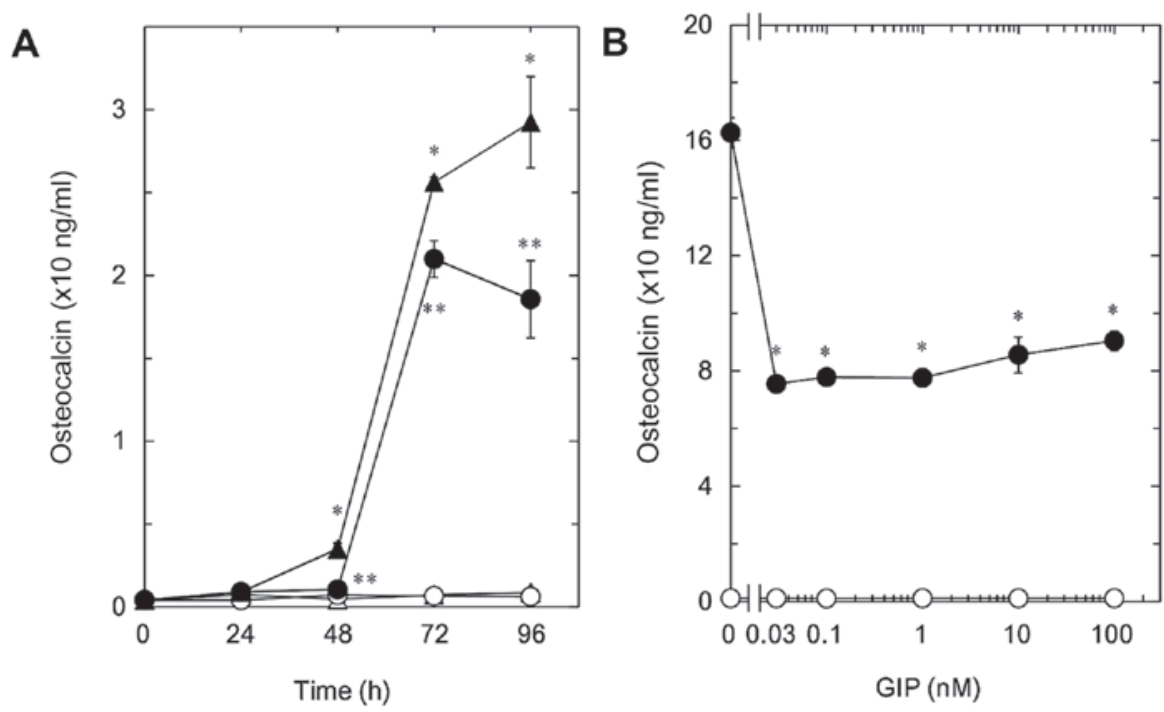

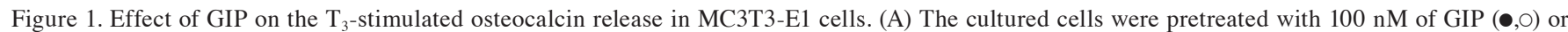
vehicle $(\mathbf{\Delta}, \triangle)$ for $60 \mathrm{~min}$, and subsequently stimulated by $10 \mathrm{nM}$ of $\mathrm{T}_{3}(\boldsymbol{\bullet}, \mathbf{\Delta})$ or vehicle $(\mathrm{O}, \Delta)$ for the indicated periods. " $\mathrm{P}<0.05$ compared to the value of the control. ${ }^{* *} \mathrm{P}<0.05$ compared to the value of $\mathrm{T}_{3}$ alone. (B) The cultured cells were pretreated with various doses of GIP for 60 min, and subsequently stimulated with $10 \mathrm{nM}$ of $\mathrm{T}_{3}(\bullet)$ or vehicle (O) for $96 \mathrm{~h}$. ${ }^{*} \mathrm{P}<0.05$ compared to the value of $\mathrm{T}_{3}$ alone. Osteocalcin concentrations in the culture medium were determined by ELISA. Each value is the mean \pm SEM of triplicate determinations from three independent cell preparations. GIP, glucose-dependent insulinotropic polypeptide; $\mathrm{T}_{3}$, triiodothyronine; ELISA, enzyme-linked immunosorbent assay.
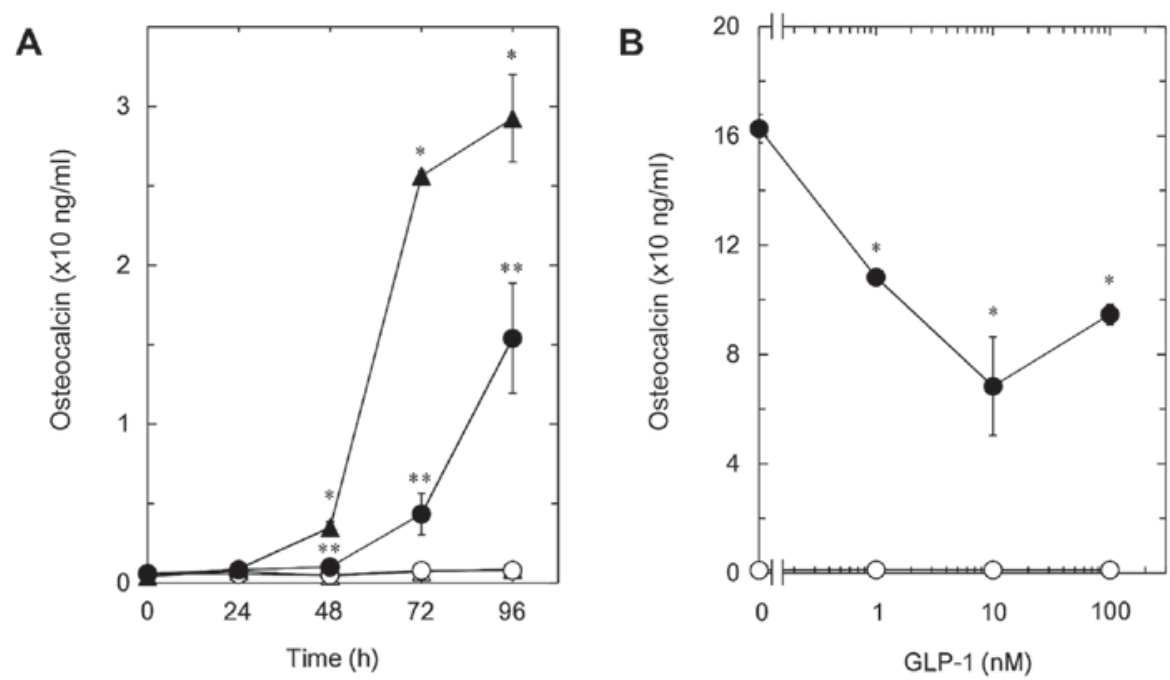

Figure 2. Effect of GLP-1 on the $\mathrm{T}_{3}$-stimulated osteocalcin release in MC3T3-E1 cells. (A) The cultured cells were pretreated with $100 \mathrm{nM}$ of GLP-1 (•,0) or vehicle $(\mathbf{\Lambda}, \Delta)$ for $60 \mathrm{~min}$, and subsequently stimulated by $10 \mathrm{nM}$ of $\mathrm{T}_{3}(\boldsymbol{\bullet}, \mathbf{\Delta})$ or vehicle $(\mathrm{O}, \Delta)$ for the indicated periods. ${ }^{*} \mathrm{P}<0.05$ compared to the value of the control. ${ }^{* *} \mathrm{P}<0.05$ compared to the value of $\mathrm{T}_{3}$ alone. (B) The cultured cells were pretreated with various doses of GLP-1 for 60 min, and subsequently stimulated with $10 \mathrm{nM}$ of $\mathrm{T}_{3}(\bullet)$ or vehicle (O) for $96 \mathrm{~h}$. "P<0.05 compared to the value of $\mathrm{T}_{3}$ alone. Osteocalcin concentrations in the culture medium were determined by ELISA. Each value is the mean \pm SEM of triplicate determinations from three independent cell preparations. GLP-1, glucagon-like peptide-1; $\mathrm{T}_{3}$, triiodothyronine; ELISA, enzyme-linked immunosorbent assay.

osteocalcin release was observed in the range between 1 and $100 \mathrm{nM}$ (Fig. 2B). A total of $10 \mathrm{nM}$ of GLP-1 caused an $\sim 60 \%$ suppression in the T3-effect.

Effects of GIP or GLP-1 on the $T_{3}$-induced expression of osteocalcin mRNA in MC3T3-E1 cells. In order to clarify whether the suppressive effects of incretins on the $\mathrm{T}_{3}$-stimulated osteocalcin release are mediated through transcriptional events or not, we examined the effects of GIP or GLP-1 on the $\mathrm{T}_{3}$-induced expression levels of osteocalcin mRNA by
RT-qPCR. Although GIP by itself had little effect on the levels of osteocalcin mRNA, it significantly attenuated the expression levels of osteocalcin mRNA induced by $\mathrm{T}_{3}$ (Fig. 3). In addition, GLP-1 reduced the $\mathrm{T}_{3}$-induced osteocalcin mRNA expression (Fig. 3).

Effects of GIP or GLP-1 on the $T_{3}$-stimulated transactivation activity of thyroid hormone responsive element in MC3T3-E1 cells. The thyroid hormone receptor belongs to the nuclear receptor superfamily (8). Therefore, we examined the effects 


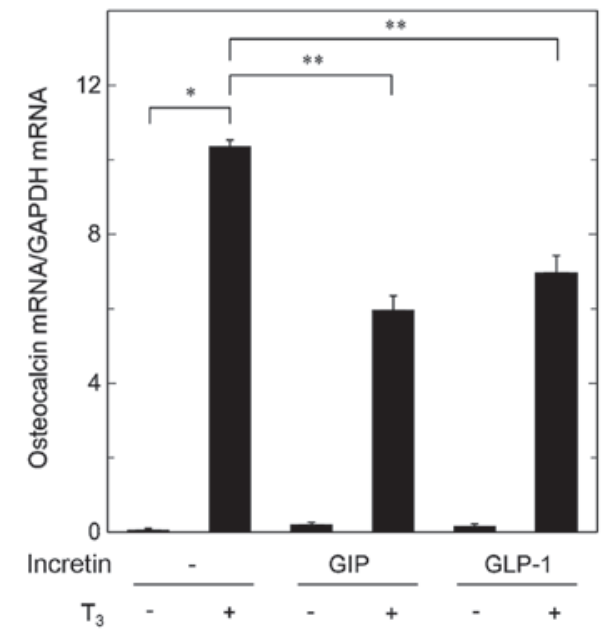

Figure 3. Effects of GIP or GLP-1 on the $\mathrm{T}_{3}$-induced expression of osteocalcin mRNA in MC3T3-E1 cells. The cultured cells were pretreated with $100 \mathrm{nM}$ of GIP, $100 \mathrm{nM}$ of GLP-1 or vehicle for $60 \mathrm{~min}$, and subsequently stimulated with $10 \mathrm{nM}$ of $\mathrm{T}_{3}$ or vehicle for $48 \mathrm{~h}$. The respective total RNA was subsequently isolated and transcribed into cDNA. The expression of osteocalcin mRNA and GAPDH mRNA were quantified by RT-qPCR. The osteocalcin mRNA levels were normalized to those of GAPDH mRNA. Each value is the mean \pm SEM of triplicate determinations from three independent cell preparations. ${ }^{*} \mathrm{P}<0.05$ compared to the value of the control. ${ }^{* *} \mathrm{P}<0.05$ compared to the value of $\mathrm{T}_{3}$ alone. GIP, glucose-dependent insulinotropic polypeptide; GLP-1, glucagon-like peptide-1; $\mathrm{T}_{3}$, triiodothyronine; RT-qPCR, reverse transcription-quantitative polymerase chain reaction.

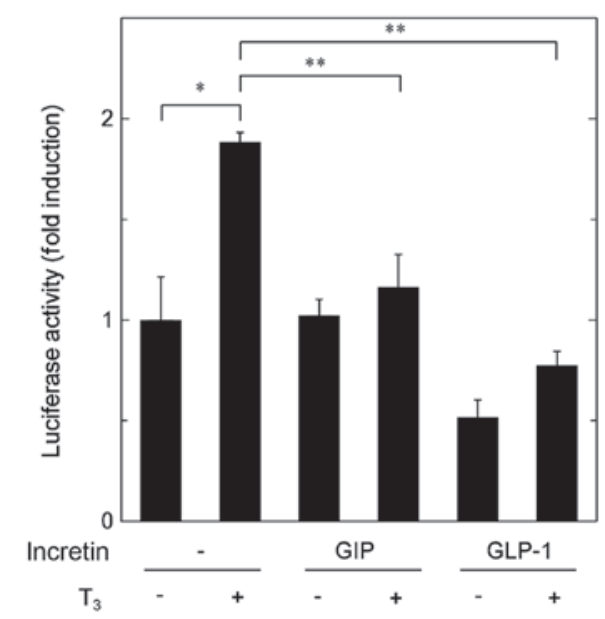

Figure 4. Effects of GIP or GLP-1 on the $\mathrm{T}_{3}$-stimulated transactivation activity of thyroid hormone responsive element in MC3T3-E1 cells. The cultured cells were pretreated with $100 \mathrm{nM}$ of GIP, $100 \mathrm{nM}$ of GLP-1 or vehicle for $60 \mathrm{~min}$ at $6 \mathrm{~h}$ after the transfection with the pDR4-Luc reporter plasmid ( $1 \mu \mathrm{g} / \mathrm{dish})$. The cells were then stimulated by $10 \mathrm{nM}$ of $\mathrm{T}_{3}$ or vehicle for $48 \mathrm{~h}$. The measurement of the luciferase activity of the cell lysates were performed using a dual luciferase reporter assay system. Each value is the mean \pm SEM of triplicate determinations from three independent cell preparations. ${ }^{~} \mathrm{P}<0.05$ compared to the value of the control. ${ }^{* *} \mathrm{P}<0.05$ compared to the value of $\mathrm{T}_{3}$ alone. GIP, glucose-dependent insulinotropic polypeptide; GLP-1, glucagon-like peptide-1; $\mathrm{T}_{3}$, triiodothyronine.

of incretins on the $\mathrm{T}_{3}$-stimulated transactivation of thyroid hormone responsive element in osteoblast-like MC3T3-E1 cells using a luciferase reporter assay. GIP markedly decreased the $\mathrm{T}_{3}$-upregulated transactivation activity (Fig. 4). In addition, GLP-1 significantly attenuated the transactivation activity stimulated by T3 (Fig. 4).

\section{Discussion}

GIP and GLP-1 are the two primary incretins secreted from the small intestine in response to ingestion of glucose or nutrients, resulting in the stimulation of insulin secretion from pancreatic $\beta$-cells (13). Regarding the effects of incretins on bone metabolism, it has been reported that GIP stimulates osteoblast differentiation via its binding to GIP-specific receptors expressed in osteoblasts (15). On the other hand, GLP-1 reportedly affects receptors expressed in thyroid parafollicular cells, resulting in upregulated synthesis of calcitonin and suppression of osteoclastic bone resorption (22). In the present study, we demonstrated that GIP and GLP-1 significantly suppressed the $\mathrm{T}_{3}$-stimulated osteocalcin release in osteoblast-like MC3T3-E1 cells. In addition, GIP and GLP-1 markedly reduced the expression levels of osteocalcin mRNA upregulated by $\mathrm{T}_{3}$. The biological functions of the thyroid hormone, one of the nuclear receptor superfamily, are mediated by binding to specific receptors in nucleus, and that the receptor-hormone complex subsequently activates the transcription of target genes (9). Thus, we examined the effect of incretins on the $\mathrm{T}_{3}$-stimulated transactivation activity of thyroid hormone responsive element assessed by a luciferase reporter assay in osteoblast-like MC3T3-E1 cells. We showed that GIP and GLP-1 significantly attenuated the $\mathrm{T}_{3}$-stimulated transactivation activity. Taking our findings into account, it is most likely that incretins reduce the $\mathrm{T}_{3}$-stimulated synthesis of osteocalcin at a point upstream of the gene transcription in osteoblast-like MC3T3-E1 cells.

Regarding the intracellular mechanism of incretins, the specific receptors for GIP or GLP-1, which belong to GTP-binding protein-coupled receptors, couple to adenylyl cyclase-activating Gs, leading to the production of cAMP (23). With regard to osteoblasts, it has been reported that both GIP and GLP-1 truly increase the intracellular cAMP levels (15). We have previously demonstrated that p38 MAP kinase is involved at least in part in the $\mathrm{T}_{3}$-stimulated osteocalcin synthesis in osteoblast-like MC3T3-E1 cells and that the adenylyl cyclase-cAMP system regulates the osteocalcin synthesis via the suppression of p38 MAP kinase activation $(11,12)$. Based on these findings, it is possible that incretins suppress the $\mathrm{T}_{3}$-stimulated osteocalcin synthesis at least in part via activation of the adenylyl cyclase-cAMP system in MC3T3-E1 cells. Further investigation is necessary to elucidate the exact mechanism of incretins in osteoblasts.

Osteocalcin is produced specifically in mature osteoblasts, and embedded in bone matrix (3). The Gla residues contained in osteocalcin are critical for the function of osteocalcin, and the osteocalcin with their fully carboxylated state binds to hydroxyapatite with a high affinity, resulting in the maintenance of calcification (3). Since osteocalcin-deficient mice reportedly present higher bone mass with strength, osteocalcin is considered a determinant factor of bone formation (4). As for incretin-effects on bone metabolism, it has been reported that incretins have inhibitory effects on bone resorption $(22,24)$. Based on the present findings showing the inhibition by GIP or GLP-1 of the $\mathrm{T}_{3}$-stimulated osteocalcin synthesis in osteoblasts, it is probable that incretins upregulate bone formation by reducing the osteocalcin levels. In addition, recent evidence suggests that osteocalcin acts 
as a potent bone-derived hormone, resulting in regulating glucose utilization and energy expenditure in myocytes and adipocytes, and stimulating insulin secretion from pancreatic $\beta$-cells $(5,25)$. Taking these findings into account, it is possible that incretins regulate whole energy metabolism by modulating osteocalcin synthesis in osteoblasts. Additionally, GIP and GLP-1 stimulate insulin secretion from pancreatic $\beta$-cells $(13,14)$. Therefore, incretins may play dual roles in the regulation of whole body energy metabolism through osteocalcin synthesis in osteoblasts and insulin secretion in pancreatic $\beta$-cells. Further investigations are required to clarify the detailed roles of incretins in bone metabolism.

In conclusion, our present findings strongly suggest that incretins inhibit the $\mathrm{T}_{3}$-stimulated osteocalcin synthesis in osteoblasts, and the suppressive effect of incretins is mediated through transcriptional levels.

\section{Acknowledgements}

We are very grateful to Mrs. Yumiko Kurokawa for her skillful technical assistance. This investigation was supported in part by Grant-in-Aid for Scientific Research (grant nos. 19591042 and 26462289) from the Ministry of Education, Science, Sports and Culture of Japan, the Research Funding for Longevity Sciences (grant no. 26-12,25-4) from the National Center for Geriatrics and Gerontology (Obu, Japan).

\section{References}

1. Karsenty G and Wagner EF: Reaching a genetic and molecular understanding of skeletal development. Dev Cell 2: 389-406, 2002.

2. Boyce BF and Xing L: Functions of RANKL/RANK/OPG in bone modeling and remodeling. Arch Biochem Biophys 473: 139-146, 2008

3. Hauschka PV, Lian JB, Cole DE and Gundberg CM: Osteocalcin and matrix Gla protein: Vitamin K-dependent proteins in bone. Physiol Rev 69: 990-1047, 1989.

4. Ducy P, Desbois C, Boyce B, Pinero G, Story B, Dunstan C Smith E, Bonadio J, Goldstein S, Gundberg C, et al: Increased bone formation in osteocalcin-deficient mice. Nature 382: 448-452, 1996.

5. Karsenty $\mathrm{G}$ and Ferron M: The contribution of bone to whole-organism physiology. Nature 481: 314-320, 2012.

6. Gogakos AI, Duncan Bassett JH and Williams GR: Thyroid and bone. Arch Biochem Biophys 503: 129-136, 2010.

7. Vestergaard P and Mosekilde L: Hyperthyroidism, bone mineral, and fracture risk - a meta-analysis. Thyroid 13: 585-593, 2003.

8. Cheng SY, Leonard JL and Davis PJ: Molecular aspects of thyroid hormone actions. Endocr Rev 31: 139-170, 2010.

9. Mullur R, Liu YY and Brent GA: Thyroid hormone regulation of metabolism. Physiol Rev 94: 355-382, 2014.
10. Kasono K, Sato K, Han DC, Fujii Y, Tsushima T and Shizume K: Stimulation of alkaline phosphatase activity by thyroid hormone in mouse osteoblast-like cells (MC3T3-E1): A possible mechanism of hyperalkaline phosphatasia in hyperthyroidism. Bone Miner 4: 355-363, 1988.

11. Ishisaki A, Tokuda H, Yoshida M, Hirade K, Kunieda K, Hatakeyama D, Shibata T and Kozawa O: Activation of p38 mitogen-activated protein kinase mediates thyroid hormonestimulated osteocalcin synthesis in osteoblasts. Mol Cell Endocrinol 214: 189-195, 2004.

12. Kanno Y, Ishisaki A, Yoshida M, Nakajima K, Tokuda H, Numata O and Kozawa O: Adenylyl cyclase-cAMP system inhibits thyroid hormone-stimulated osteocalcin synthesis in osteoblasts. Mol Cell Endocrinol 229: 75-82, 2005.

13. Baggio LL and Drucker DJ: Biology of incretins: GLP-1 and GIP. Gastroenterology 132: 2131-2157, 2007.

14. Holst JJ: The physiology of glucagon-like peptide 1. Physiol Rev 87: 1409-1439, 2007.

15. Bollag RJ, Zhong Q, Phillips P, Min L, Zhong L, Cameron R, Mulloy AL, Rasmussen H, Qin F, Ding KH, et al: Osteoblastderived cells expressfunctional glucose-dependent insulinotropic peptide receptors. Endocrinology 141: 1228-1235, 2000.

16. Bollag RJ, Zhong Q, Ding KH, Phillips P, Zhong L, Qin F, Cranford J, Mulloy AL, Cameron R and Isales CM: Glucose-dependent insulinotropic peptide is an integrative hormone with osteotropic effects. Mol Cell Endocrinol 177: 35-41, 2001.

17. Sanz C, Vázquez P, Blázquez C, Barrio PA, Alvarez MM and Blázquez E: Signaling and biological effects of glucagon-like peptide 1 on the differentiation of mesenchymal stem cells from human bone marrow. Am J Physiol Endocrinol Metab 298: E634-E643, 2010.

18. Sudo H, Kodama HA, Amagai Y, Yamamoto S and Kasai S: In vitro differentiation and calcification in a new clonal osteogenic cell line derived from newborn mouse calvaria. J Cell Biol 96: 191-198, 1983.

19. Kozawa O, Tokuda H, Miwa M, Kotoyori J and Oiso Y: Cross-talk regulation between cyclic AMP production and phosphoinositide hydrolysis induced by prostaglandin E2 in osteoblast-like cells. Exp Cell Res 198: 130-134, 1992.

20. Zhang W, Yang N and Shi XM: Regulation of mesenchymal stem cell osteogenic differentiation by glucocorticoid-induced leucine zipper (GILZ). J Biol Chem 283: 4723-4729, 2008

21. Simpson DA, Feeney S, Boyle C and Stitt AW: Retinal VEGF mRNA measured by SYBR green I fluorescence: A versatile approach to quantitative PCR. Mol Vis 6: 178-183, 2000.

22. Seino Y and Yabe D: Glucose-dependent insulinotropic polypeptide and glucagon-like peptide-1: Incretin actions beyond the pancreas. J Diabetes Investig 4: 108-130, 2013.

23. Godinho RO, Duarte T and Pacini ES: New perspectives in signaling mediated by receptors coupled to stimulatory $G$ protein: The emerging significance of cAMP effux and extracellular cAMP-adenosine pathway. Front Pharmacol 6: 58, 2015.

24. Lecka-Czernik B: Safety of anti-diabetic therapies on bone. Clin Rev Bone Miner Metab 11: 49-58, 2013.

25. Lee NK and Karsenty G: Reciprocal regulation of bone and energy metabolism. Trends Endocrinol Metab 19: 161-166, 2008 . 